\title{
Modos e sentidos da inovação no jornalismo
}

MODES AND MEANINGS OF INNOVATION IN JOURNALISM

\author{
LElaide Martins \\ Jornalista, mestre em Comunicação Social pela Universidade Metodista de São Paulo e doutora \\ em Ciências do Desenvolvimento Socioambiental pela Universidade Federal do Pará (UFPA). \\ Docente do Programa de Pós-Graduação em Comunicação, Cultura e Amazônia da Faculdade \\ de Comunicação da UFPA. Coordenadora do Grupo de Pesquisa Interações e Tecnologias na \\ Amazônia e integrante da Rede Jortec/SBPJor. \\ E-mail: elaidemartins@gmail.com
}

Recebido em 8 de agosto de 2017. Aprovado em 31 de janeiro de 2018.

\section{Resumo}

Esta pesquisa busca refletir e identificar distintos modos, aspectos e sentidos da inovação no jornalismo. Debruçando-se sobre os relatórios de inovação do New York Times, adota-se a análise documental, uma vertente do estudo de caso embasada na obra dos autores Yin, Duarte e Clemente Júnior, e as categorias de análise sistematizadas por Rosseti, fundamentadas na classificação aristotélica do conceito de mudança. A partir de Barbosa, Mazza, Giacomini Filho, Silverman e Fonseca, esta importante discussão contribui para a compreensão do conceito de inovação no jornalismo e aponta tendências no campo da comunicação.

Palavras-chave: Modos de inovação. Jornalismo. The New York Times.

\begin{abstract}
This research seeks to reflect and identify different ways, aspects and meanings of innovation in journalism. In view of the innovation reports of the New York Times, the documentary analysis was adopted, being a kind of case study founded on Yin, Duarte and Clemente Júnior's studies, and on the analysis categories systematized by Rosseti, which, in turn, are based on Aristotle's typology of the concept of change. Starting from Barbosa, Mazza, Giacomini Filho, Silverman, and Fonseca, this important discussion contributes to understand the concept of innovation in journalism and points out trends in the field of communication.
\end{abstract}

Keywords: Modes of innovation. Journalism. The New York Times. 


\section{Introdução}

Etimologicamente, a palavra "inovação" se origina do termo latino "innovare", que significa "incorporar o novo", "trazer a novidade para dentro" (MAZZA, 2014), relacionando-se ao ato de inovar (FUCK; VILHA, 2012). Por mais que seja constituído do mesmo princípio do verbo inventar, isto é, mudar paradigmas, o conceito de inovação possui suas especificidades. Enquanto inventar é um termo associado à geração de uma ideia ou produto totalmente novo - incluindo desde o desenvolvimento de pequenos artefatos até invenções mais marcantes, como a pólvora, a escrita, a lâmpada, os meios de transporte e de comunicação, entre outros - podemos entender inovação como a introdução de diferenciais ou melhorias em tais descobertas, reconfigurando-as.

O início das reflexões sobre o conceito de inovação é, comumente, atribuído aos trabalhos do economista e cientista político Joseph Schumpeter, que foi ministro das finanças da Áustria em 1919 e professor na Universidade de Harvard a partir de 1932. Esse austro-americano é considerado o primeiro teórico clássico da inovação e notabilizou-se pela apresentação do conceito de "destruição criativa" como elemento essencial do capitalismo, cuja dinâmica cria e destrói, produzindo uma contínua mutação que "incessantemente revoluciona a estrutura econômica a partir de dentro, incessantemente destruindo a velha, incessantemente criando uma nova" (SCHUMPETER, 1984, p. 113). Ou seja, para esse autor, a inovação relaciona-se às novas combinações.

Em suas pesquisas a respeito da contribuição de Schumpeter (1942 apud MAZZA, 2013, p. 33-34) para o conceito de inovação, Mazza, por sua vez, afirma que esse autor considerava inovação "a reforma ou revolução de um padrão de produção a partir da exploração de uma invenção, ou, de forma mais geral, uma possibilidade tecnológica original, para a promoção de um novo produto ou serviço”. Nesse sentido, à introdução do novo acrescenta-se a combinação de recursos (MAZZA, 2013, 2014), atributo da inovação que tem sido percebido nos mais diferentes campos. No da comunicação, é por meio das interfaces tecnológicas e novas mídias que a inovação se evidencia mais nitidamente.

Todavia, a inovação está presente também no impacto social das novas tecnologias de comunicação e informação, no novo receptor, agora produtor e interativo, nos processos cognitivos, nas linguagens, na estética e até mesmo em novas abordagens metodológicas e teóricas de comunicação. Isso porque a inovação é um fenômeno social, simbólico e tecnológico, presente em toda sociedade contemporânea midiatizada e pode perpassar todo o campo da Comunicação. (ROSSETI, 2013, p. 64). 
Baseada na classificação aristotélica do conceito de mudança, essa autora adota oito categorias para designar distintos modos e significados de inovação, compreendendo os seus mais diferentes processos e classificando-a em: inovação substancial, que diz respeito a uma invenção ou criação absoluta, isto é, algo inédito, completamente novo; qualitativa, referente à novidade, à qualidade de novo; quantitativa, quando há crescimento, multiplicação daquilo que já existe; relativa, quando a inovação relaciona-se com produto ou processo de algo que já existe, constituindo-se como diversificação ou diferenciação em relação a esse aspecto preexistente; espacial, quando há transposição para outro lugar diferente da origem, "a passagem de um gênero a outro, de um sentido a outro"; temporal, mudança que gera o novo no tempo, acontece como um processo contínuo de evolução ou aperfeiçoamento e pode ocorrer na passagem do tempo; ativa, quando o sujeito é inovador, pratica a ação; e passiva, ocasião em que o objeto inovado sofre a mudança capaz de torná-lo inovador (ROSSETI, 2013, p. 70).

Tais conceitos serão retomados mais adiante, quando os usaremos como categorias de análise para identificar os modos, significados e as ações de inovação no jornal norte-americano New York Times. Esse jornal foi escolhido como objeto de estudo não somente por ser um dos mais antigos e influentes periódicos do mundo, mas por ser reconhecido por romper paradigmas e impor novos modelos. É um jornal que investe na inovação para sobreviver à crise que atinge o jornalismo contemporâneo, amplificada pelo avanço das tecnologias emergentes e pelos mais distintos desafios que trazem para o campo da comunicação.

Além das categorias de análise citadas anteriormente, o procedimento metodológico aqui adotado será associado à análise documental, uma das vertentes do estudo de caso (CLEMENTE JÚNIOR, 2012; DUARTE, 2006; YIN, 2001), realizada a partir das prioridades e recomendações do Relatório do Grupo 2020, publicado em janeiro de 2017 pelo NYTimes. Antes, porém, convém abordar conceitos, aspectos e sentidos da inovação no jornalismo, a fim de contextualizar e compreender essa temática e melhor conhecer seu estado da arte.

\section{Alguns conceitos e aspectos para compreender a inovação no jornalismo}

A inovação no jornalismo pode ser compreendida sob certos aspectos, seja nas formas narrativas, nos processos produtivos, nos dispositivos tecnológicos e/ou interativos ou mesmo nas etapas de circulação e consumo das informações. Em sua abordagem sobre práticas para a inovação nas organizações de notícias, Silverman (2015) discute o 
papel das lideranças e condições para criar uma cultura e uma estrutura abertas para a inovação, gerar e buscar ideias inovadoras e coletar um feedback da audiência. $\mathrm{O}$ autor acredita que a inovação assume muitas formas, mas a define "como o processo de trazer novas práticas, cultura e produtos vivos para dentro de uma organização" (Ibid., tradução nossa). Ao mesmo tempo que esse processo busca preservar valores fundamentais, procura atendê-los de forma inovadora.

Acima de tudo, no entanto, um olhar mais atento sobre a literatura e a prática da inovação revela ser uma combinação de processo, estrutura e cultura. Não é uma coisa ou produto; inovação é sobre como sua organização funciona e se move para a frente. (Ibid., tradução nossa).

Emum contextode convergênciajornalística(SALAVERRÍA;NEGREDO,2008), Barbosa (2014, p. 1) propõe uma reflexão sobre o dinamismo enquanto característica-chave dos produtos jornalísticos, considerando "os dispositivos móveis, as bases de dados e a distribuição multiplataforma como agentes de inovação, renovação e reconfiguração" do jornalismo contemporâneo. Sua abordagem apresenta perspectivas, tendências e desafios para as organizações desse setor e elenca agentes que potencializam a dinamicidade nos sites jornalísticos.

Em sua reflexão, a autora ampara-se em Meyer (2010) para apresentar a inovação como forma de conseguir lucro e adota Pavlik (2001) para explicar que o "dinâmico quer dizer conteúdo noticioso mais fluido, que permite melhor representação dos eventos e processos na vida real" (PAVLIK, 2001 apud BARBOSA, 2014, p. 2). Para Barbosa (2014, p. 1), um produto jornalístico digital e dinâmico "é aquele cujo conteúdo é continuamente renovado, inter-relacionado, contextualizado, trabalhado segundo distintos formatos multimídia".

Esse panorama vem contribuindo significativamente para a renovação e/ou criação de distintos modelos narrativos que passaram a ser adotados no jornalismo, como as narrativas hipermídia, multimídia(LONGHI, 2010), transmídia(ALZAMORA; TÁRCIA, 2012a, 2012b; MARTINS, 2012), imersivas (TÁRCIA, 2011; CANAVILHAS; BACCIN, 2015; MARQUES, 2016; ROCHA, 2016) e as de realidade virtual (DIAS, 2016; MARQUES, 2016; SCOTT, 2016). Além desses aspectos, as inovações no jornalismo podem se manifestar de outras maneiras.

Elas seriam produtos novos, desenvolvimento de novos processos, interações individuais e grupais emergentes na organização, na concepção do negócio e no tratamento de questões nos diversos ambientes (SOUSA, 2006). A criação de um anúncio, o lançamento de uma editoria jornalística, a elaboração original de uma peça de campanha publicitária, um novo ângulo de 
abordagem de uma matéria na imprensa representam inovações, uma vez que desenvolvem processos e até novos produtos na estrutura organizacional. (GIACOMINI FILHO, 2015, p. 78).

Mudanças nessa estrutura têm uma relação direta com a gestão, que muitas vezes precisa romper com antigos modelos organizacionais para tentar acompanhar as transformações nos produtos das empresas - caso do NYTimes, como indica o Relatório 2020. Para Fonseca (2015), mudanças de ordem tão paradigmática exigem a renovação de todo o sistema, incluindo profissionais, regras, rotinas e modelos de negócios. Ele ressalta "a importância do legado de Schumpeter e sua visão economicista da inovação que nos faz lembrar fatores como a competitividade e geração de riquezas", elementos que movem as mudanças na gestão.

Além de realizarem abordagens contextuais e conceituais e investigarem elementos e manifestações da inovação, Giacomini Filho (2015), Fonseca (2015) e Fonseca e Barbosa (2016) trazem, assim como Rosseti (2013), contribuições metodológicas para os estudos da inovação. Giacomini Filho (2015, p. 77) apresenta "elementos de responsabilidade social organizacional (RSO) como fatores contributivos para inovações no conteúdo publicitário e jornalístico".

Já Fonseca (2015) apresenta categorias de análise para a inovação em revistas jornalísticas para tablets, tomando como base o conceito de convergência de conteúdos e, juntamente com Barbosa (2016), propõe uma ferramenta para identificar inovações. "A inovação no jornalismo [...] está relacionada a um contexto da indústria midiática configurada a partir das características da comunicação móvel" (FONSECA; BARBOSA, 2016, p. 108). Tanto a incorporação de dispositivos móveis pelo jornalismo quanto a sua aproximação com as redes sociais são fatores que têm impulsionado a inovação em diferentes aspectos - e as ações inovadoras representam possiblidades concretas de renovar produtos e ampliar e/ou fidelizar seu público, como veremos a seguir.

\section{Jornalismo orientado para a inovação}

Em janeiro de 2017, um dos mais importantes jornais do mundo, o The New York Times publicou o Relatório do Grupo 2020 com as estratégias e aspirações da redação elaboradas por sete jornalistas que passaram o ano anterior "conduzindo centenas de conversas com jornalistas do Times e com pessoas de fora; estudando o comportamento do leitor em grupos focais" (LEONHARDT et al., 2017, tradução nossa). Esse grupo deu prosseguimento ao Comitê de Inovação, cujo relatório de 2014 teve repercussão em âmbito internacional: primeiro porque era um documento interno que vazou para a imprensa 
e, segundo, porque admitia as falhas do jornal e a necessidade de repensar sua cultura tradicional, a fim de não prejudicar o seu crescimento digital.

O grupo fez um balanço dos avanços e dificuldades do tradicional diário e apresentou cinco sugestões fundamentais: criar uma equipe incumbida de monitorar o desenvolvimento da audiência do jornal; criar uma equipe de analistas da redação, avaliando tendências, como as matérias mais lidas e retransmitidas pelos leitores; criar uma equipe de estrategistas, voltada para estudar o desempenho do jornal tradicional e o "Times" digital, buscando se adequar rapidamente a novas tendências; colaborar com os setores comercial e de assinaturas; e dar prioridade à contratação para o segmento de jornalismo digital. (MELLO, 2014, n.p.).

Em sua análise acerca do Relatório de Inovação 2014', Fontoura (2015, p. 187) mostra que muitos dos desafios ali expostos haviam sido apontados "anteriormente através da academia e literatura especializada" e que o documento "trata-se de um relatório interno que expunha as falhas do New York Times nos últimos anos em seus esforços digitais. Falhas de plataforma, de processo, de distribuição, entre outras".

Além de diagnosticar o peso da sua tradição, as tendências de mercado e elencar ações para inovação (ABBRUZZESE, 2014; DÓRIA, 2014; MELLO, 2014; TANZER, 2014), esse relatório serviu de guia para renovar o jornalismo e a gestão do NYTimes. Segundo Nguyen (2015) e Soares (2017), todas as mudanças previstas no relatório foram introduzidas, inclusive as estratégias de usar multiplataformas para "impulsionar sua audiência na internet e nos celulares para elevar as vendas com anúncios digitais" (ALPERT, 2015), bem como o reforço de treinamento da equipe em 2016 (LEONHARDT et al., 2017 tradução nossa). Tais ações contribuíram para mudar a cultura da redação. No entanto, o Relatório do Grupo 2020 diferencia-se do Relatório de Inovação, segundo seus próprios membros, em dois aspectos importantes:

Primeiro, tivemos o benefício de trabalhar em estreita colaboração com a liderança do Times no ano passado para começar a implementar mudanças. Como resultado, este relatório [do grupo 2020] não pretende ser o guia detalhado para a mudança como foi o Relatório de Inovação [...]. Este relatório é, em vez disso, uma declaração de princípios, prioridades e objetivos - um guia para ajudar os membros da redação a entender mais plenamente a direção que o The Times está seguindo [...]. Em segundo lugar, o grupo 2020 foi encarregado de questionar o pressuposto subjacente à primeira frase do Relatório de Inovação: "O New York Times está ganhando no jornalismo". Nós estamos realmente ganhando, mas não em uma

1 Innovation Report é um relatório interno, datado de 24 de março de 2014. Foi vazado pela imprensa em maio de 2014, publicado pelo BuzzFeed News, em versão incompleta e em preto e branco, e carregado na plataforma Scribd.com por Amanda Wills, editora do site Mashable, em versão completa e colorida (THE NEW YORK TIMES, 2014). 
escala suficiente para atingir os objetivos da empresa ou sustentar nossas aclamadas operações de redação. (Ibid., tradução nossa).

Dentre esses objetivos, o principal é duplicar a receita digital da empresa para U\$800 milhões em 2020. A estratégia é aumentar o volume de assinaturas digitais, inclusive para outros países. "Com todos os progressos que fizemos, ainda não construímos um negócio digital suficientemente grande para apoiar uma redação que possa cumprir nossas ambições" (Ibid., tradução nossa).

Dessa forma, o Grupo 2020 estabeleceu algumas prioridades visando à mudança de três grandes áreas: reportagem, equipe e gestão. Na primeira, a orientação é praticar um jornalismo mais visual, com o uso de infográficos, mapas, fotos e vídeos; mixar textos e formas jornalísticas mais tradicionais com formatos digitalmente nativos, expandindo a maneira de contar histórias, adotando um tom menos informal e inovando briefings, sessões informativas por turno e ao vivo, "boletins informativos por e-mail, alertas, FAQs, painéis de avaliação, áudio, vídeo". Além disso, o relatório recomenda que o jornalismo de serviço seja valorizado e que se incentive a participação e o engajamento do público para que este se sinta parte da comunidade do jornal.

Quanto à equipe, a ordem é alinhar suas habilidades às demandas do jornal, tornando-o uma fonte ainda mais influente para conquistar a confiança da audiência, a ponto de fazê-la pagar por seu conteúdo. Para isso, pretende-se investir em treinamento "para combinar experiência e conhecimentos com as novas e poderosas ferramentas de narrativas à nossa disposição" e ampliar a contratação de talentos que ajudem o jornal a passar "de papéis tradicionais, com foco em impressão, para novos papéis, com foco em multimídia, como jornalistas visuais, que moldam a forma e o conteúdo" (Ibid., tradução nossa). Por conseguinte, as contratações de alta prioridade serão as relacionadas à criação, como repórteres, editores gráficos, fotógrafos, cinegrafistas, editores backfielders e outras categorias de impacto direto sobre o jornalismo, visando a realidade digital.

Enquanto princípio, o relatório recomenda aumentar a diversidade da equipe da redação contratando mais negros, mulheres, jovens, indivíduos do subúrbio e estrangeiros, a fim de produzir reportagens mais ricas e envolventes. Essa é uma estratégia vital para ampliar o público jovem e internacional. Por último, a busca pela inovação também inclui repensar o trabalho freelance, "expandindo-o em algumas áreas e encolhendo-o em outras" (Ibid., tradução nossa), revendo, dessa forma, as seções e abordagens às quais este vem sendo destinado.

Sobre a terceira área, a gestão, o Grupo 2020 aponta um conjunto de recomendações para mudar a forma de trabalhar, voltadas, especialmente, para o distanciamento da cultura do impresso. Por mais mudanças que o jornal tenha feito nas duas últimas 
décadas, reconhece-se que suas estruturas organizacionais ainda são oriundas do jornal físico. Dentre os desafios para avançar enquanto veículo inovador está a missão, para cada departamento, de deixar claro à sua equipe quais são seus objetivos, estabelecer metas e acompanhar seu progresso, bem como redefinir sucesso a partir de uma métrica mais sofisticada do que pageviews, a fim de medir o valor de um artigo para atrair e reter assinantes - compreendendo-se que a métrica não é perfeita e que é preciso combinar avaliações quantitativas e qualitativas.

Ademais, os jornalistas entrevistados pelo grupo sugeriram que os editores gastassem menos tempo reorganizando os parágrafos de suas reportagens e mais tempo com o início delas, discutindo sua abordagem e dando um enfoque mais conceitual. A redação e a equipe de produtos devem trabalhar juntas, a fim de melhor compreender o que cada uma faz e, assim, alcançar maior eficácia. Por fim, deve-se reduzir o papel predominante que a mídia impressa desempenha na organização e no ritmo do NYTimes e, ao mesmo tempo, fazer um jornal físico ainda melhor. Para isso, recomenda-se incentivar a colaboração entre os jornalistas que cobrem o mesmo assunto, definindo-se qual o público-alvo e como se espera que este consuma o conteúdo produzido.

Tais orientações trazem desafios que a busca por inovação impõe tanto ao jornalismo quanto aos modelos de negócio das empresas do setor, que precisam considerar o público em seus processos. Como bem ressalta o Relatório do Grupo 2020, na era das plataformas de mídia social, "a experiência de ler, ver e ouvir o nosso trabalho tem de ser tão atraente quanto o próprio jornalismo" (Ibid., tradução nossa). Por isso, é preciso estar aberto a mudanças e experimentações e perceber os aspectos culturais, e não apenas tecnológicos das inovações.

A ideia de que The Times deve mudar pode parecer assustadora e contraintuitiva. Continuamos a ser a organização de notícias mais influente no país, com um grupo grande e crescente de leitores fiéis. Mas a noção de uma mudança no New York Times não é nova. Grande parte do sucesso da instituição ao longo do século passado dependeu de sua capacidade de mudar. [...] A revolução digital, no entanto, não parou. As mudanças nos hábitos dos nossos leitores - as maneiras que eles recebem informações e notícias e se envolvem com o mundo - têm acelerado nos últimos anos. [...] Como os hábitos e as necessidades dos leitores mudaram, o The Times mudou com eles. Nossos valores não se alteraram, mas sim a forma de expressá-los. (Ibid., tradução nossa).

É importante lembrar que as mudanças, sejam negativas ou positivas, estão associadas à inovação. No jornalismo, muitas resultaram da incorporação de novas ferramentas tecnológicas aos processos de produção, difusão e consumo de conteúdo, mas hoje 
muitas outras nascem do desejo de oferecer novas experiências - manifestadas nos mais diferentes modos e sentidos de inovar, como veremos adiante.

\section{Os modos e sentidos de inovação no NYTimes}

A partir das diretrizes estabelecidas pelo Relatório do Grupo 2020, vamos identificar e analisar as categorias adotadas por Rosseti (2013) para designar distintos modos e sentidos de inovação no NYTimes. Como já dito, esse relatório orienta-se a partir de três grandes tópicos (reportagem, equipe e gestão), examinados aqui por meio do reconhecimento das categorias utilizadas pela autora, baseadas na classificação aristotélica do conceito de mudança. Convém esclarecer, como bem ressalta Rosseti (2013, p. 67), que a concepção de mudança é fundamental para a inovação, considerando-se que toda mudança traz o novo, sendo capaz de gerar novos estados, entretanto, "por ser um conceito genérico que perpassa várias categorias, ele não pode ser classificado como uma das categorias de inovação". Portanto, está na essência das categorias, mas não se trata de uma delas.

No primeiro tópico do relatório, podemos tomar como exemplo as narrativas das grandes reportagens multimídias, também denominadas long form (LONGHI, 2010), verticais (BARBOSA; NORMANDE; ALMEIDA, 2014) ou especiais multimídia, cujo divisor de águas foi o especial "Snow Fall: the avalanche at tunnel creek", produzido pelo próprio NYTimes em 2012 (BECKER; BARREIRA, 2013) - antes mesmo da publicação do Relatório de Inovação 2014. Além do impacto causado por seu caráter multimidiático marcado pela combinação de textos e pela mistura de formas jornalísticas mais tradicionais com formatos digitais - bem como pela natureza do próprio assunto abordado (uma tragédia), esse especial virou modelo para sites jornalísticos do mundo todo e foi amplamente discutido pela academia.

Esses tipos de narrativas representam uma inovação substancial no jornalismo, uma vez que constituem algo inédito, completamente novo, assim como indicam uma inovação qualitativa, ligada à criatividade - aquela que "produz a novidade" (ROSSETI, 2013, p. 69). Tais modos de inovação podem ser facilmente reconhecidos nas narrativas transmídia e multimídia.

Ademais, é importante ressaltar que além da visualidade, o Relatório do Grupo 2020 recomenda a ampliação das formas de contar histórias, aproximando-se da ideia de criação ou expansão do universo, um dos conceitos-chave da narrativa transmídia sistematizados por Jenkins (2009). Outro tipo de inovação encontrado na reportagem refere-se ao aspecto espacial, quando a "inovação pode estar fora do produto comunicacional ou do processo comunicativo como um lugar, uma situação, uma posição" (ROSSETI, 2013, p. 70). Nesse sentido, 
assume contornos de deslocamento, transição ou passagem, podendo ser vista, segundo a autora, como um salto de um lugar a outro, uma transposição. Isso pode ser percebido na visualidade de certas narrativas do NYTimes, especialmente quando vídeos são usados.

O conceito de transposição pode ajudar a entender a inovação na Web, quando: a transposição é um ato que pode gerar inovação, e pode favorecer o surgimento de novas qualidades e propriedades que não existiam no gênero de partida e que são trazidas à luz no gênero de chegada, tal qual um processo tradutório ou de recriação. Tratam de transposições pensadas como arranjos ou adaptações de gêneros, de mídias e de sentidos. Tais arranjos implicam mudanças nas linguagens e, ao mesmo tempo, promovem inovações de formato, sintaxe ou conteúdo. (Ibid.).

Ainda no que concerne às reportagens, destaca-se o aspecto temporal da inovação, isto é, o fato de que o novo é gerado em relação ao tempo. No caso do NYTimes, as transformações em suas narrativas, marcadas pela transposição para a plataforma digital, já vêm acontecendo há pelo menos duas décadas, indicando evolução ou certa ruptura com o modo de fazer determinado produto - a exemplo do formato das reportagens. Como os relatórios do jornal sinalizam, "a inovação pode acontecer como um processo contínuo de evolução ou aperfeiçoamento" (Ibid.).

Quanto à gestão, a inovação quantitativa, que se dá pelo crescimento, indicando a multiplicação daquilo que já existe (Ibid.), é bastante evidente nos dados de faturamento do jornal. O NYTimes alcançou quase U\$500 milhões em 2016 em receita puramente digital e pretende chegar a U\$800 milhões até 2020, meta que dá nome ao seu último relatório.

Considerando-se que uma inovação relativa acontece quando algo que já existe é feito de forma diferenciada ou diversificada (Ibid.), tomamos como exemplo o processo de faturamento do jornal, que além da publicidade e assinaturas do jornal impresso, passou a contar também com uma parcela significativa de assinantes de conteúdo digital. Como já dito, a inovação pode ser relativa ao produto ou ao processo, constituindo-se como diferenciação e/ou diversificação. Nessa análise, isso também pode ser percebido nas mudanças previstas para outro tópico do relatório: a equipe. A orientação é ampliar a diversidade a partir de contratações de grupos minoritários (negros, mulheres, suburbanos, estrangeiros etc.), enquanto princípio e estratégia para a expansão do público, inclusive com assinantes fora do país.

Ainda no que se refere às mudanças na equipe, é possível perceber uma inovação em termos de ação, aquela que acontece quando o sujeito é inovador, exercendo um papel ativo. As práticas que combinam o conhecimento e a experiência de antigos jornalistas com o uso de novas ferramentas para construir narrativas seriam um exemplo de inovação ativa na equipe? E o trabalho conjunto entre redação e equipes de produtos? Mais do que 
inovação ativa da equipe, esses exemplos, bem como a atuação do público, podem representar também uma inovação de ação do próprio jornal enquanto sujeito.

Como exemplo da condição ativa do público, podemos citar sua atuação ao perceber erros, falta de nuances e/ou de nitidez nos textos dos jornalistas, chamando-os "rapidamente no Twitter, Facebook e em outros lugares" (LEONHARDT et al., 2017, tradução nossa). Esse comportamento da audiência reflete seu papel ativo enquanto sujeito inovador que pratica a ação.

Ademais, o público pode inovar em termos de ação usando as seções de comentários do NYTimes e engajando-se na comunidade do jornal, mesmo que esses espaços ainda estejam aquém da demanda. "Sabemos por pesquisas e anedotas que os leitores valorizam as oportunidades limitadas que oferecemos para participar da discussão" (Ibid., tradução nossa). Todavia, os responsáveis pelo relatório reconhecem a necessidade de promover mais interações e engajar sua audiência.

Talvez nada construa a fidelidade do leitor tanto quanto o engajamento - o sentimento de ser parte de uma comunidade. E os leitores do New York Times são muito uma comunidade. Eles querem conversar uns com os outros e aprender uns com os outros, não só sobre comida, livros, viagem, tecnologia e palavras cruzadas, mas também sobre política e assuntos externos. (Ibid., tradução nossa).

Engajamento diz respeito ao envolvimento da audiência inclusive com a complexidade da narrativa. Está presente em grande parte dos conceitos-chave da narrativa transmídia (JENKINS, 2009), revelando uma participação mais ativa do público, tanto na construção como na circulação de conteúdo, principalmente por meio das redes sociais. Entretanto, engajamento significa muito mais do que reações do público às notícias publicadas, sendo capaz de provocar relacionamentos mais duradouros com o produto e despertar sentimentos, contribuindo, dessa forma, para a fidelização da audiência.

A inovação passiva, por sua vez, está submetida à categoria da paixão, "em que o objeto inovado sofreu a ação que gerou nele a inovação. É o efeito da inovação que gera um produto inovado" (ROSSETI, 2013, p. 70). Os editores do Relatório 2020 perceberam o valor da paixão enquanto modo de inovação, sugerindo narrativas mais dinâmicas e envolventes para fidelizar o público. "Em termos simples, precisamos de menos cabeça e mais coração em nossa narrativa. A emoção não é algo que tendemos a abraçar, e deveríamos. É um dos principais motores de lealdade!” (LEONHARDT et al., 2017, tradução nossa).

Assim, na qualidade de inovação passiva, a paixão acontece quando o objeto é inovado, pois nessa categoria a inovação é intrínseca ao objeto e o tem como fim, a exemplo 
das narrativas verticalizadas do jornal. É o novo que surge como resultado do processo de inovação - ao contrário da inovação em termos de ação, que diz respeito ao sujeito, e não ao objeto em si (ROSSETI, 2013). Portanto, não é apenas mais um modo, mas um modo importante de gerar inovações e novos sentidos para o jornalismo contemporâneo.

\section{Considerações finais}

Discorrer sobre inovação no jornalismo não é uma tarefa simples, até porque suas manifestações se dão de várias maneiras e ela se faz presente não apenas nos produtos, mas também nos processos, na equipe e na gestão. Como diz Rosseti (2013, p. 64), "a inovação é um fenômeno social, simbólico e tecnológico, presente em toda sociedade contemporânea midiatizada". Nesta pesquisa, vimos em Silverman (2015) que não se trata somente de uma coisa ou produto, mas de algo que se relaciona ao fluxo e ao funcionamento das empresas de notícias. É, portanto, um procedimento multiforme com modos e significados distintos, que podem se manifestar tanto na ação de um sujeito inovador como no decurso e no resultado do processo de inovação, fazendo o novo chegar ao produto, como bem demonstrou Rosseti (2013). Nos seus distintos modos, o dinamismo é um agente importante de inovação para o jornalismo, conforme a abordagem de Barbosa (2014).

Ao olhar para os modos e aspectos da inovação analisados neste trabalho, percebemos que o conceito de mudança possui fundamental importância para a compreensão dos sentidos da inovação. Da capacidade de mudar depende o sucesso de muitas empresas de notícias. Assim, analisando um jornal secular como o NYTimes, fundado em $1851 \mathrm{e}$ cuja tradição sustenta-se na qualidade de seu produto, percebe-se a complexidade que os processos inovadores podem representar, especialmente quando a sua dinâmica impõe certa velocidade de mudança. Mais do que conviver ou aceitar tais transformações, é preciso enraizá-las e considerar seus desdobramentos, a exemplo de ter que lidar com uma audiência mais crítica e participativa e precisar entender seu comportamento para não perdê-la para a concorrência.

Apesar do teor extremamente autocrítico do Grupo 2020, destacamos que o seu relatório dirige pouca atenção para a forte presença das redes sociais no ecossistema midiático e suas relações com o jornalismo, uma tendência cada vez mais explícita. Além disso, apesar de falar em diversidade, o relatório não trata de ferramentas de acessibilidade para seu público - realidades que precisam ser consideradas em tempos de convergências.

As mudanças de comportamento, valores e princípios que a sociedade sofre com o passar dos tempos afetam sua própria cultura. E os aspectos culturais precisam ser 
pensados pela redação e pela gestão das empresas de jornalismo, uma vez que a cultura é um fenômeno comum, compartilhado. É preciso que se reconheça que a mentalidade e, consequentemente, a dinâmica das redações, hoje, estão passando por transformações. Os tempos são de experimentações, de um ecossistema midiático diversificado, de múltiplas plataformas de produção, compartilhamento e consumo de conteúdo, inclusive, gratuito. Em meio a um mercado altamente competitivo, muitas empresas de jornalismo sentem-se forçadas a reestruturar seus modelos de negócios, construindo novos hábitos para que o público volte a consumir seu conteúdo diariamente. Nesse sentido, a inovação vem sendo buscada como uma forma de cooptar e até mesmo fidelizar esse público.

No entanto, apesar de todas as renovações e inovações e da consecutiva necessidade de flexibilização e de ajuste às mudanças do tempo, duas características precisam sobreviver no jornalismo: qualidade e, por consequência, credibilidade. Mantê-las frente a todas as transformações que se revelam em nosso dia a dia é um dos grandes desafios do jornalismo na contemporaneidade.

\section{Referências}

ABBRUZZESE, J. The full New York Times innovation report. Mashable, New York, May 16, 2014. Business. Disponível em: <https://goo.gl/CgsAJr>. Acesso em: 24 jan. 2017.

ALPERT, L. New York Times recorre a Facebook e Apple para atrair leitores jovens. The Wall Street Journal, [S.1.], Aug. 4, 2015. Articles. Acesso em: 24 jan. 2017.

ALZAMORA, G.; TÁRCIA, L. A narrativa jornalística transmidiática: considerações sobre o prefixo trans. In: LONGHI, R.; D’ANDRÉA, C. (Org.). Jornalismo convergente: reflexões, apropriações, experiências. Florianópolis: Insular, 2012a. p. 15-32.

Convergência e transmídia: galáxias semânticas e narrativas emergentes em jornalismo. Brazilian Journalism Research, Brasília, DF, v. 8, n. 1, p. 22-35, 2012b.

BARBOSA, S. Agentes de inovação, renovação e de reconfiguração para o jornalismo em tempos de convergência. Revista de Cibercomunicación, Santiago de Compostela, v. 1, n. 1, p. 1-8, 2014.

BARBOSA, S.; NORMANDE, N.; ALMEIDA, Y. Produção horizontal e narrativas verticais: novos padrões para as narrativas jornalísticas. In: ENCONTRO ANUAL DA ASSOCIAÇÃO NACIONAL DOS PROGRAMAS DE PÓS-GRADUAÇÃO EM COMUNICAÇÃO - COMPÓS, 23., 2014, Belém. Anais... Belém: UFPA/PPGCOM, 2014. p. 1-19.

BECKER, B.; BARREIRA, I. Snow fall: uma avalanche de criatividade e de desafios para o ensino de jornalismo. Contracampo, Niterói, v. 28, n. 3, p.73-91, 2013.

CANAVILHAS, J.; BACCIN, A. Contextualization in hypermedia news report: narrative and immersion. Brazilian Journalism Research, Brasília, DF, v. 1, n. 1, p. 10-27, 2015. 
CLEMENTE JÚNIOR, S. S. Estudo de caso x casos para estudo: esclarecimentos acerca de suas características e utilização. In: SEMINÁRIO DE PESQUISA EM TURISMO DO MERCOSUL, 7., 2012, Caxias do Sul. Anais... Caxias do Sul: UCS, 2012. p. 1-12.

DIAS, R. Realidade virtual é um novo meio de comunicação, dizem debatedores. Folha de S.Paulo, São Paulo, $1^{\circ}$ abr. 2016. Caderno Tec. Disponível em: <https://goo.gl/yRxvno>. Acesso em: 24 jan. 2017.

DÓRIA, T. Raio-X da inovação no NYTimes. Blog Tiago Doria, Boston, 19 maio 2014. Disponível em: $<$ https://goo.gl/G6NugW>. Acesso em: 13 fev. 2017.

DUARTE, M. Y. M. Estudo de caso. In: DUARTE, J.; BARROS, A. (Orgs.). Métodos e técnicas de pesquisa em comunicação. $2^{\mathrm{a}}$. ed. São Paulo: Atlas, 2006.

FONSECA, A. A. Convergência e inovação jornalística em revistas para tablets: uma proposta de categorias de análise. In: SIMPÓSIO INTERNACIONAL DE CIBERJORNALISMO, 6., 2015, Campo Grande/MS. Anais... Campo Grande: UFMS, 2015. 20 p.

FONSECA, A.; BARBOSA, S. A trajetória das revistas para tablets no brasil: criando uma ferramenta para identificação de inovações. In: MARTINS, E.; PALACIOS, M. (Orgs.). Ferramentas para análise de qualidade em ciberjornalismo. Volume 2: aplicações. Covilhã: LABCOM.IFP, 2016. p. 107-143.

FONTOURA, M. C. Desafios do jornalismo: uma análise acadêmica do relatório de inovação do The New York Times. Alceu, Rio de Janeiro, v. 16, n. 31, p. 187-200, jul./dez. 2015.

FUCK, M. P.; VILHA, A. M. Inovação tecnológica: da definição à ação. Contemporâneos, [S.1.], n. 9, p. 1-21, nov./abr. 2012.

GIACOMINI FILHO, G. A responsabilidade social como fator de inovação para a comunicação. Comunicação \& Inovação, São Caetano do Sul, v. 16, n. 31, p. 77-93, maio/ago. 2015.

JENKINS, H. Revenge of the origami unicorn: seven principles of transmedia storytelling. Confessions of an ACA-fan, California, Dec. 12, 2009. Disponível em: <https://goo.gl/mniyMS>. Acesso em: 29 ago. 2012.

LEONHARDT, D. et al. Journalism that stands apart. The report of the 2020 Group. The New York Times, New York, Jan. 2017. Disponível em: <https://goo.gl/nj6j2r>. Acesso em: 13 fev. 2017.

LONGHI, R. R. O nome das coisas: em busca do especial multimídia. Estudos em Comunicação, Covilhã, v. 2, n. 7, p. 149-161, maio 2010. Disponível em: <https://goo.gl/zm6Byg>. Acesso em: 13 fev. 2017.

MARTINS, E. Telejornalismo na era digital: aspectos da narrativa transmídia na televisão de papel. Brazilian Journalism Research, Brasília, DF, v. 8, n. 2, 2012.

MARQUES, J. P. Realidade virtual e jornalismo imersivo: anotação dinâmica de peças noticiosas em vídeo $360^{\circ} .2016 .105$ f. Dissertação (Mestrado em Multimédia) - Universidade do Porto, Porto, 2016.

MAZZA, C. L. S. Capacidades dinâmicas e inovação em serviços: um estudo de caso das práticas de sustentabilidade empresarial do Laboratório Sabin. 2013. 161 f. Dissertação (Mestrado em

$48 \frac{\text { Comunicação \& Inovação, PPGCOM/USCS }}{\text { v. 19, n. } 39 \text { (35-49) jan-abril } 2018}$ 
Administração) - Faculdade de Economia, Administração, Contabilidade e Ciência da Informação e Documentação, Universidade de Brasília, Brasília, DF, 2013.

Afinal, o que é inovação? Portal Educação, São Paulo, 29 abr. 2014. Administração e Gestão. Disponível em: <https://goo.gl/sqVpob>. Acesso em: 10 fev. 2017.

MELLO, P. T. 'New York Times’ anuncia inovação para a era digital de notícias. O Globo, Rio de Janeiro, 9 jun. 2014. Economia. Disponível em: <https://goo.gl/NCXhcm>. Acesso em: 15 maio 2014.

NGUYEN, A. Como o New York Times mudou desde seu relatório de inovação. IJNet, Washington, DC, 5 jun. 2015. Disponível em: <https://goo.gl/dLZ1S3>. Acesso em: 24 out. 2017.

ROCHA, G. G. Jornalismo imersivo: explorações e caminhos para apropriações do acontecimento jornalístico a partir de experiências com dispositivos de realidade virtual. In: CONGRESSO DE CIÊNCIAS DA COMUNICAÇÃO NA REGIÃO SUL, 17., 2016, Curitiba. Anais... Curitiba: PUCPR, 2016. p. 1-15.

ROSSETTI, R. Categorias de inovação para os estudos em comunicação. Comunicação \& Inovação, São Caetano do Sul, v. 14, n. 27, p. 63-72, jul./dez. 2013.

SALAVERRÍA, R.; NEGREDO, N. Periodismo integrado: convergencia de medios y reorganización de redacciones. Barcelona: So190, 2008.

SCOTT, C. Now is a good time for publishers to invest in virtual reality. Journalism.co.uk, London, Apr. 13, 2016. Disponível em: <https://goo.gl/S4C7sV>. Acesso em: 24 jan. 2017.

SCHUMPETER, J. A. Capitalismo, socialismo e democracia. Rio de Janeiro: Zahar, 1984.

SILVERMAN, C. The best practices for innovation within news organizations. American Press Institute, Arlington, May 27, 2015. Disponível em: <https://goo.gl/SbiVfB>. Acesso em: 24 jan. 2017.

SOARES, N. 7 medidas do New York Times para continuar liderando a inovação no jornalismo. Linkedin, [S.1.], 25 jan. 2017. Disponível em: <https://goo.gl/NAwZf2>. Acesso em: 10 fev. 2017.

TANZER, M. Exclusive: New York Times Internal Report painted dire digital picture. BuzzFeed News, USA, May 15, 2014. Disponível em: <https://goo.gl/GEFKch>. Acesso em: 24 jan. 2017.

TÁRCIA, L. Narrativa transmídia em jornalismo de imersão e newsgame. In: ENCONTRO NACIONAL DE PESQUISADORES EM JORNALISMO, 9., 2011, Rio de Janeiro. Anais... Rio de Janeiro: SBPJor, 2011.

THE NEW YORK TIMES. Innovation Report 2014. The New York Times, New York, Mar. 24, 2014. Disponível em: <https://goo.gl/Mg6RwM>. Acesso em: 10 fev. 2017.

YIN, R. K. Estudo de caso: planejamento e métodos. 2. ed. Porto Alegre: Bookman, 2001. 